\title{
2
}

\section{ECONOMIC THEORY AND PRACTICAL LESSONS FOR MEASURING EQUALITY OF OPPORTUNITY IN THE ASIA-PACIFIC REGION ${ }^{1}$}

\author{
Miles Corak
}

\section{Introduction and major messages}

My use of the word 'practical' in the title of this paper should not necessarily be interpreted as 'feasible'. Some of the suggestions I make for the development of a set of statistics appropriate for the measurement of equality of opportunity certainly are feasible, and while some can be introduced and used almost immediately, others can only be put into practice over a longer horizon and may well require a commitment of statistical resources. The point is to clarify the elements of a dashboard of equality-of-opportunity indicators that can be used to promote evidencebased policy by making comparisons, gauging progress, and possibly even setting targets. 'Practical' lessons are those that can in principle be put into practice, but also those that are grounded in our understanding of the theory of intergenerational mobility and equality of opportunity.

\footnotetext{
1 This paper is based upon and adapts my 2016 paper Economic theory and practical lessons for measuring equality of opportunities (No 2016/02, OECD Statistics Working Papers. Paris).
} 
Theory, of course, rarely if ever gives direct guidance to empirical analysis and public policy. I draw two threads from economic theory, and pull them as long as I possibly can to inform specific recommendations for policymakers concerned with the measurement and monitoring of equality of opportunity in the Asia-Pacific countries. Economic theory first suggests that descriptive statistics associated with intergenerational mobility do not speak directly to equality of opportunity without accepting a value judgement that children should not be held responsible for circumstances beyond their control; and, second, the process of child development encourages a focus on different skills and competencies, as well as different stages in a child's life. These two threads of thought lead to three suggestions.

The first is to use data appropriate for the country at hand - and, indeed, where possible promote the development and use of new data, whether associated with the administration of government programs, survey data supplemented with retrospective questions, or linked survey and administrative data - to estimate summary measures of intergenerational mobility. These statistics include a measure of the average rate of income mobility, and a measure of directional rank mobility: (1) the intergenerational earnings elasticity, which can be thought of as a complement to cross-sectional indicators of inequality like the Gini coefficient; and (2) intergenerational income transition matrices, which depict the degree and direction of child mobility according to each parental rank.

The second suggestion is to develop measures of absolute mobility and, in particular, develop a poverty line based upon the monetary resources associated with possibly discrete changes in the lack of upward mobility for children whose parents are in the lower part of the income distribution. The headcount ratio of children living in families with less than this level of monetary resources is a more timely statistic than the intergenerational elasticity that can be regularly published, and offers an early warning sign of changes in intergenerational mobility.

The final suggestion is to describe socio-economic gradients in the health and wellbeing, numeracy, and literacy of young children and those in their early teens. This involves regularly publishing a host of appropriate statistics associated with important skills and competencies of children in a way that is framed by the theory of equality of opportunity. This should be based upon surveys of children in their early teen years, and 
children on the cusp of primary school. These age-appropriate statistics should be included - along with measures of family background in repeatedly administered cross-sectional surveys.

\section{What is intergenerational mobility?}

There is no single answer to the question of what comprises intergenerational mobility, and certainly there is credibility in many of the different measures used across the various social sciences. Economic analysis is rooted in a perspective that stretches back to Francis Galton, whose work dates to the late 1800 s, and continues to resonate today through a simple model of 'regression to the mean':

$$
\ln Y_{i, t}=\alpha+\beta \ln Y_{i, t-1}+\epsilon_{i, t}
$$

where $Y$ is an outcome that we are interested in, usually taken to be permanent income by economists, $i$ indexes families, and $t$ generations. The best guess of a child's adult earnings (generally expressed in natural logarithms) is just the average income of his or her birth cohort - which can be thought as indicated by $\alpha$ - plus two deviations from the average, the first being some fraction of the earnings of his or her parent or parents, as represented by $\beta$ - and the other representing residual influences not correlated with parental income. The value of $\beta$, the intergenerational income elasticity - usually estimated by least squares - is the parameter of interest, indicating to what degree the relative advantages or disadvantages of the parent are transmitted to the child. $\beta$ expresses this in percentage terms, and is generally found to be positive but less than one: as it approaches zero, mobility is complete (with the best guess of a child's adult earnings being the cohort average); as it approaches one, mobility is limited and, in the extreme, children occupy the same position in the income distribution as their parents. Negative values indicate an intergenerational reversal in economic status, and values greater than one indicate divergence from, rather than regression to, the average.

As an exercise in description, this statistic is no more than what it is, though sometimes it is made out to be much more, possibly reflecting the fact that what is central to academic analysis may not align perfectly with what is of interest in public policy. It is the best overall measure of the average degree of intergenerational mobility. But, much in the same way that the Gini coefficient offers a broad indication of cross-sectional 
inequality, the intergenerational elasticity, like the Gini, misses important nuances. The elasticity assumes linearity in the mobility process, mobility for the very rich being the same for the very poor. As such, it offers no specific sense of directional movement should that vary across the parental income distribution; the upward movement from rags to riches may not be the same as the downward movement from riches to rags. Further, the elasticity cannot be given a causal interpretation and, though it informs discussions of 'equality of opportunity', it is not, on its own, a measure of this concept.

There is a long list of careful studies suggesting this statistic varies across the rich countries, lying somewhere between 0.4 and 0.6 for Italy, the United Kingdom and the United States; and as low as 0.2 or less in some Nordic countries. Björklund and Jäntti (2011), Black and Devereux (2011), Blanden (2013), Corak (2013; 2006), Mulligan (1997), and Solon $(2002 ; 1999)$ review this literature. While this statistic has been estimated for men and women, for a host of different measures of income and earnings - both individual and family; for earnings; total market income; and for income after taxes and transfers - the largest number of estimates that permit cross-country comparisons refer to the market earnings of fathers and sons. This version of the statistic has been estimated for many more countries, with the World Bank offering the most recent and comprehensive list covering more than 70 countries (Narayan et al. 2018). Figure 2.1 uses this list, presenting the available intergenerational earnings elasticity for the Asia-Pacific countries. These statistics roughly refer to the adult outcomes of children born in the 1960s and 1970s.

There is a significant range, from as high as 0.702 to as low as 0.181 . The World Bank report notes that mobility tends to be higher in highincome countries (Narayan et al. 2018, 139). The intergenerational elasticities among the 75 countries listed in the World Bank report range from 1.095 to 0.113 , with a global unweighted average of 0.515 . The range of estimates in Figure 2.1 comes close to spanning the global extremes. Most of the higher income countries in the region have higher rates of mobility, whether compared to others in the region but also globally. Countries in South Asia tend to have lower mobility than those in East Asia and the Pacific. 


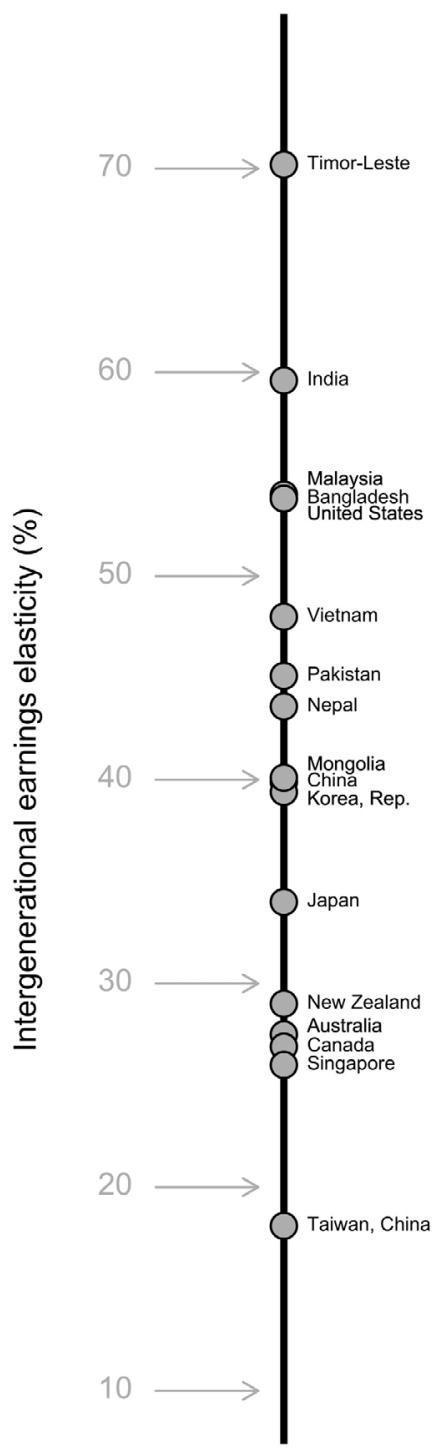

Figure 2.1. Seventeen AsiaPacific countries ranked according to World Bank estimates of intergenerational earnings elasticity

Source. Derived by the author using the Global Database on Intergenerational Mobility (GDIM) (2018) (Development Research Group, World Bank. Washington DC)
An intergenerational earnings elasticity as high as 0.702 implies a significant fraction of income inequality will be passed on across generations and, on its own, suggests a sluggish rate of regression to the mean. In this scenario, a child's adult income will continue to be correlated with his or her grandparents' income, putting aside any independent influence grandparent income may have on the transmission process. An intergenerational elasticity as low as 0.181 suggests that any advantage that parents may have echoes only weakly among the next generation, with no tie at all between child and grandparent incomes and income advantage or disadvantage being wiped out in two generations. India is estimated to stand at the upper end of this ranking with an intergenerational elasticity of 0.596 . The elasticity in China is 0.399, somewhat lower than India or, for that matter, the United States, but nonetheless a relatively high elasticity reflecting lower mobility than almost half of the countries in this list.

Finally, this statistic on its own makes no reference to absolute differences or directional changes: whether a generation is making more or less than the previous generation, whether particular children are making more or less than their parents, or whether 
mobility in one country is higher or lower than another because of more or less mobility in either an upward direction from the bottom, or a downward direction from the top.

Public policy is motivated not just by the overall average rate of mobility, but also by the direction of movement, particularly the chances of intergenerational cycles of low income, the chances of moving from the bottom to the middle or upper ranks, and even the chances of intergenerational cycles of privilege that may block children from lower or middle family backgrounds moving into the top ranks.

Even so, this is a valuable statistic as a backdrop to public policy discussion, and offers a complement to the Gini coefficient and other measures of cross-sectional inequality. It is a broad summary measure of mobility, indicating the degree to which relative income advantages are passed on between successive generations. But if there is confidence that a particular country has the statistical infrastructure in place to accurately produce this statistic, then it would do well to supplement it with a somewhat fuller descriptive account of mobility. As mentioned, the regression to the mean model assumes the mobility process is linear, and offers no sense of movement in specific directions. It is usefully complemented with the transition matrix between parent and child ranks in their respective income distributions. These transition matrices, an example of which is offered in Table 2.1, give a sense of both upward and downward mobility, and permit the public policy community to assess the degree of mobility from any set of parents with a common rank in the income distribution.

Table 2.1. Quintile transition matrix between parent and child incomes in the United States

\begin{tabular}{|l|c|c|c|c|c|}
\hline & \multicolumn{5}{|c|}{ Parent quintile } \\
\hline Child quintile & $\mathbf{1}$ & $\mathbf{2}$ & $\mathbf{3}$ & $\mathbf{4}$ & $\mathbf{5}$ \\
\hline 1 & $33.7 \%$ & $24.2 \%$ & $17.8 \%$ & $13.4 \%$ & $10.9 \%$ \\
\hline 2 & $28.0 \%$ & $24.2 \%$ & $19.8 \%$ & $16.0 \%$ & $11.9 \%$ \\
\hline 3 & $18.4 \%$ & $21.7 \%$ & $22.1 \%$ & $20.9 \%$ & $17.0 \%$ \\
\hline 4 & $12.3 \%$ & $17.6 \%$ & $22.0 \%$ & $24.4 \%$ & $23.6 \%$ \\
\hline 5 & $7.5 \%$ & $12.3 \%$ & $18.3 \%$ & $25.4 \%$ & $36.5 \%$ \\
\hline
\end{tabular}

Source. Chetty et al. (2014), Table II

This example is drawn from Chetty et al. (2014) using administrative data on the income taxation of the population of children born in the early 1980s, their filings at roughly the age of 30 and those of their parents 
decades earlier. The information in Table 2.1 shows that children raised by parents in the bottom 20 per cent of the income distribution have only a 7.5 per cent chance of moving to the top fifth, while those raised by parents in the top have an almost 37 per cent chance of being in the top fifth of their generation. It is in this sense that patterns of directional movement can be described.

But this example also makes clear that the data requirements may be particularly challenging, necessitating not just a direct intergenerational link between parent and child adult incomes - a longitudinal link of members of the same family that may have to span decades - but also relatively large sample sizes in order to derive transition probabilities between distinct parts of the income distribution. The use of high quality and comprehensive income tax data has allowed researchers in some of the rich countries to produce transition matrices as defined as finely as percentiles (Chetty et al. 2014; Corak 2018). This may not be possible, and poses a data challenge for other countries.

This said, promoting the upward mobility of children raised by bottom income parents is likely to be a relevant policy issue for all countries, and particularly those moving from low- and middle-income status to high-income status. The intergenerational earnings elasticity informs this discussion even under the assumption of linearity. A slow regression to the mean might raise the importance of not letting families fall too far below average income because mobility is so low. But a non-linear process heightens the matter even more, and may also give this public policy discussion particular salience in countries that have a high degree of regression to the mean.

What is left unanswered is just what income levels are critical to lowering the risk of an intergenerational stickiness of status at the bottom: where should we draw a poverty line if our concern is the risk associated with the loss of upward mobility? Further, should this be entirely income based, or should it include other crucial resources needed to promote upward mobility? Ranks don't answer these questions, and we can't fully answer them without an appreciation of the underlying causes. The development and regular publication of a poverty line of this sort - a measure of the minimal monetary and other resources below which the chances of the intergenerational transmission of poverty are distinctly higher and its associated headcount ratio would be a valuable complement to existing poverty lines. 


\section{What is equality of opportunity?}

The degree of regression to the mean in incomes, and associated transition matrices, are central descriptive statistics of intergenerational mobility. Without them we cannot begin a discussion about equality of opportunity. But they are not measures of equality of opportunity. John Roemer makes the case that a transition matrix in which all entries are the same - a completely level playing field with no differences in the association between child outcomes and family backgrounds - does not reflect a definition of equality of opportunity that most citizens would consider acceptable (Roemer 2004). It would involve public policy levelling all possible playing fields, compensating for all possible circumstances and, by implication, significantly curtailing the role of family autonomy in the raising of children.

For Roemer, equality of opportunity means that inequities of outcome are not defensible when they are the result of different 'circumstances' (Roemer 2000). To make this distinction, we need to know to what degree individuals are responsible for their outcomes in life: in other words, to what extent are these outcomes the result of circumstances beyond an individual's control (for which they should be compensated), and to what extent do they reflect an individual's effort (for which they should be responsible)?

His philosophical analysis of these issues asks us to accept that drawing a line between 'circumstance' and 'effort' requires a value judgement. Values are certainly a part of economic analysis, and it is fair to suggest that they mainly enter the analysis as a way of ranking the desirability of alternative outcomes. Philosophers, and a good deal of experimental evidence, however, tell us that most people also care about the ways in which outcomes are obtained: process matters. Equality of opportunity is about process, and value judgements are inherent to defining it.

As such, the development of statistics useful for public policy addressed to equality of opportunity cannot escape the need to make an explicit value judgement. Without doing so, theory will offer little guidance for the conduct of policy, and no practical suggestions for the development of appropriate statistical indicators beyond the purely descriptive. But this is nothing new. For example, while it is rare for the statistical agencies to 
adopt 'official' poverty lines, all these countries, or their supra-national representatives, draw these lines using some value judgement on the degree of absolute and relative deprivation that in some sense is not acceptable.

It is not self-evident what 'circumstances' policymakers should seek to level in order to promote equality of opportunity, but one way to advance the discussion is to focus measurement on children. Roemer and Trannoy suggest that 'all inequality regarding children should be counted as due to circumstances, and none to effort. More specifically, children should only become responsible for their actions after an "age of consent" is reached (which may vary across societies), so both nature and nurture fall within the ambit of circumstances for the child' (Roemer \& Trannoy 2016, 1308). This may be a value judgement that most citizens are willing to accept, particularly when paired with a human rights perspective, informed by the UN Convention on the Rights of the Child, which almost all countries have ratified.

Economic theory makes clear that intergenerational mobility is determined by a host of factors, and that we can't parse these out by simply looking at the intergenerational income elasticity. Becker and Tomes (1986; 1979) offer a standard and widely used economic model underscoring this point. A simplified version would be based on the following three equations:

$$
\begin{aligned}
& \ln Y_{t}=\phi \ln Y_{t-1}+\gamma H_{t}+\lambda E_{t}+v_{t} \\
& H_{t}=\delta E_{t}+\theta \ln Y_{t-1} \\
& E_{t}=\alpha+b E_{t-1}+V_{t}
\end{aligned}
$$

The model is recursive, and this formalisation also links with increasingly accepted notions of child development. In my notation, $t$ indexes generations, with $t$ referring to children and $t-1$ to their parents. Children inherit from their parents an endowment associated with their underlying personality, competencies, or perhaps family culture $(E)$, to the degree given by $h$. This endowment influences the development of their human capital $(H)$, which may also be influenced by their parents' status, usually income status (but also possibly education status), to the degree given by $\theta$, with $\theta \geq 0$. Human capital, in turn, is an important influence on adult outcomes, $(Y)$, but endowments continue to play a direct role, as may also be the case for parental status, according to the values of $\lambda$ and $\phi$. 
The important message, even at this level of abstraction, is that $\beta$, as Solon (2004) makes clear, will be a composite of:

- the degree of inheritability of innate endowments or family culture (b)

- the strength of the causal association between family circumstances and a child's human capital $(\theta)$

- the returns to those components of human capital $(\gamma)$, a clear marker for the degree of labour market inequality

- any direct influence parental status may have on earnings outcomes of children in adulthood $(\phi)$, through networks or nepotism, or through endowments $(\lambda)$.

The observation that one country has a different $\beta$ from another, or that there are upward or downward trends in $\beta$ over time and cohorts within a country is not informative for public policy directed to equality of opportunity because this coefficient does not identify a particular causal force, and because we have not articulated as a public policy objective which - if any - of these factors cut against accepted notions of equality of opportunity.

If we focus on equation (1), most citizens might agree that differences in incomes associated with nepotism in the hiring process should be eliminated so that those with well-connected parents are not earning more than other children who are just as highly educated or have the same level of other characteristics that influence earnings. And most citizens might also agree on eliminating differences in outcomes associated with endowments that do not reflect differences in productivity - skin colour, height, beauty, and ethnicity. But we cannot know whether or not this is the case from observing $\beta$, which would also be influenced by the returns to characteristics, whether innate or through the efforts that went into getting more schooling and skills, that are associated with productivity differentials. A statistic derived from an equation like $\ln Y_{i, t}=\alpha+\beta \ln Y_{i, t-1}$ $+\epsilon_{i, t}$ only starts this conversation, and a public policy conversation more closely tied to Roemer's notion of equality of opportunity first requires an understanding of how labour markets work and how access to jobs is determined, and then moves to placing emphasis on children, focusing on equation (2), the development of human capital, and its association with parental status. 
This model may be too simplified to describe how human capital is developed. We need to appreciate the developments in the economics, psychology and child development literatures suggesting equation (2) might be more appropriately represented as a series of recursive equations, each representing a stage in which children develop specific competencies that then set a stage, and raise or dampen the risks of fully developing through the next stage. An important interaction in this process is that between the early years and subsequent development, as summarised by Jim Heckman's metaphor that 'skills beget skills' (Heckman \& Mosso 2014). We need to also appreciate that the dimensions of human capital relevant for adult earnings may also be multidimensional and include not just cognitive skills but also aspects of health and wellbeing, as well as personality and other non-cognitive skills. Formal schooling and the associated credentials may only partially indicate or develop these skills.

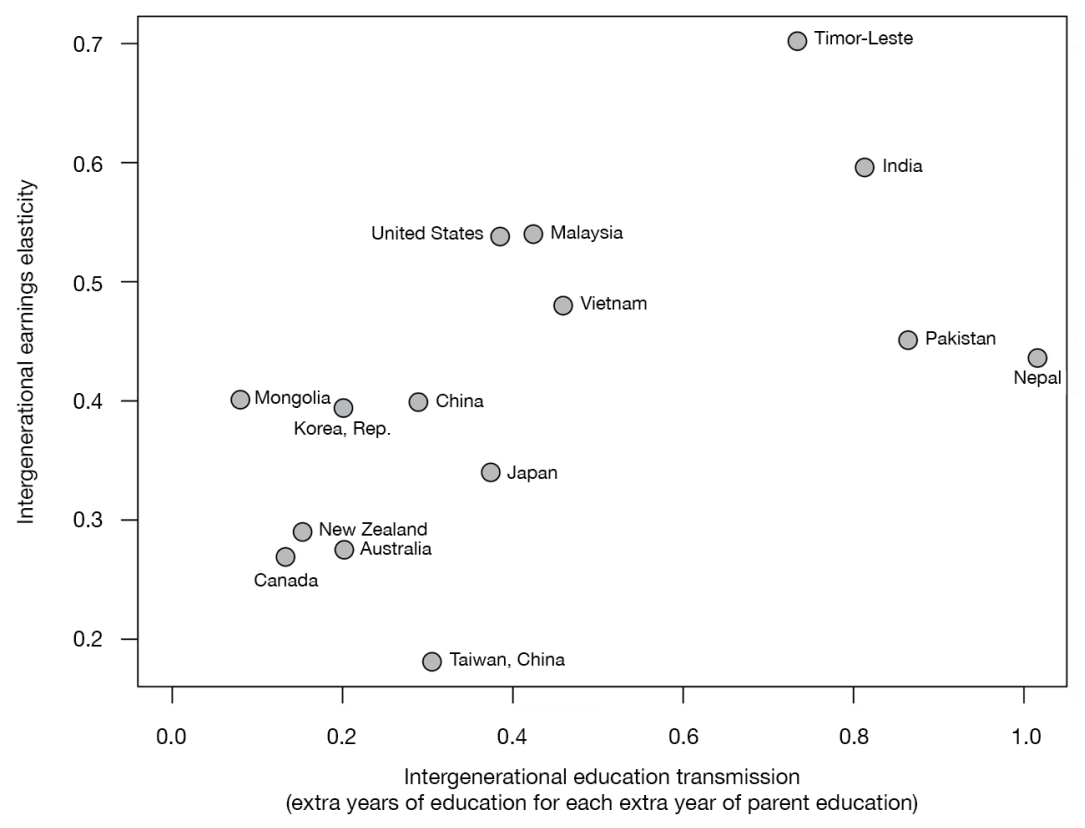

Figure 2.2. Intergenerational education transmission (extra years of education for each extra year of parent education). The intergenerational transmission of earnings is positively correlated with the intergenerational transmission of education among 15 Asia-Pacific countries

Source. Derived by the author using the Global Database on Intergenerational Mobility (GDIM) (2018) (Development Research Group, World Bank. Washington DC) 
This said, statistical markers of equality of opportunity should be informed by the subsystem of recursive equations represented by equation (2). My view is that parental education is a preferred indicator of socio-economic status for these purposes, reflecting the capacity of parents to make both monetary and non-monetary investments in their children. We might profitably rewrite equation (2) to be $H_{t}=\delta E_{t}+\theta H_{t-1}$, letting $H$ represent years of schooling, with lower values of $\theta$ representing a diminished role of circumstance in determining child outcomes.

This is the perspective taken in Figure 2.2, which ranks 15 Asia-Pacific countries along two dimensions. First, the horizontal direction offers an indicator of the degree to which education is transmitted between generations, a particular version of $\theta$. Narayan et al. (2018) derive this statistic as the regression coefficient between child and parent years of schooling. Their derivation is based upon children old enough to have completed schooling, and whose parents have less than tertiary education. The latter restriction prevents a 'ceiling' bias from influencing the results since there is an upper limit to the amount of schooling that can be obtained. This intergenerational transmission statistic should be interpreted as the extra years of schooling a child is expected to obtain for each additional year of schooling among their parents. This is a summary measure of the relationship between the monetary and non-monetary resources to which parents may have access, including preferences and family culture, and the educational attainments of their children, a very broad representation of equation (2) and the subsystems it summarises. The intergenerational transmission of schooling varies significantly between the countries in the Asia-Pacific region for which this indicator is available. This gradient varies from as low as 0.08 to as high as 1.016: in some countries this playing field is relatively level, but in others extremely steep.

The figure also ranks the countries vertically by the intergenerational elasticity used in Figure 2.1 (Bangladesh and Singapore not appearing for lack of the intergenerational education data). There is a clear positive association between intergenerational mobility of incomes and education. The more strongly children's years of schooling are associated with their parents' years of schooling, the more tightly associated are child-parent incomes: a sharper socio-economic gradient in the development of human capital tends to suggest a sharper gradient in incomes. Broadly speaking, socio-economic differences in human capital development underpin, in some measure, socio-economic differences of incomes. 
We can look to socio-economic inequalities in the human capital of children to refine a statistical dashboard depicting equality of opportunity. The intergenerational earnings elasticity and transition matrices are broad-picture statistics with long time lags, but the correlation in Figure 2.2 suggests that early warning signs of the direction in which they may move are offered by the socio-economic gradients in the development of human capital during important transitions in children's lives. These gradients are associated with a causal understanding of the process and can be produced more regularly, and in a more timely fashion, to directly inform public policy.

These statistics and even more finely defined statistics directly measuring skills, variations in children's literacy, numeracy, or social skills according to their parents' education, are abstractions neglecting variations in parental preferences. Nonetheless, we may imagine that regardless of parental preferences or capacities, all children should grow up in a way that develops their capacity to become all that they can be, and to function normally in our societies as they exist. So explicit measurement of these capacities at each important stage of child development is important for informing public policy, and measuring equality of opportunity in a way that is at least one level deeper than just description, even if in some degree it continues to formally remain that.

Figure 2.3, drawn from a four-country study by Bradbury et al. (2015), offers an example of competency in various dimensions of mathematics by 14-year-old children in the United States, according to whether the parent with the highest education held a college degree (labelled 'High education' in the figure) or, at the other extreme, had no more than a high school diploma (labelled 'Low education'). On average, less than four in 10 teens on the cusp of high school have mastered manipulating fractions. This average outcome is something public policymakers may wonder about, and they may even also wonder about the fact that just less than six in 10 children from the most advantaged backgrounds have mastered this skill. Overall averages - indicated by the horizontal lines in the figure - may continue to be a concern as policymakers are likely to have a clearer sense of what is socially acceptable in these sorts of domains, regardless of a child's family circumstances. If this is so, then they may also wonder about the falling away of competency among children with less-advantaged backgrounds. This dimension of the discussion opens a natural window onto equality of opportunity. 


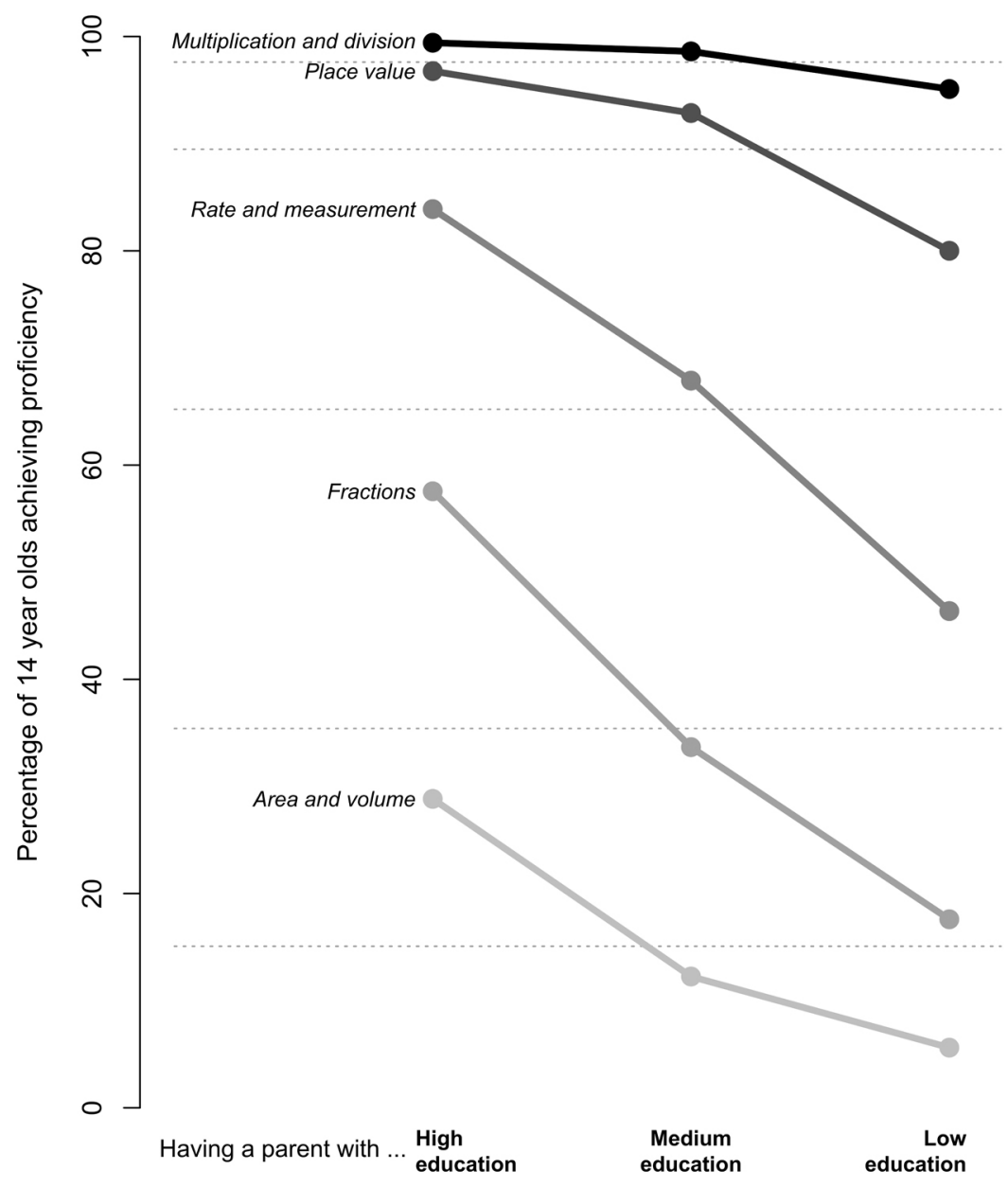

Figure 2.3. Proficiency in mathematics among 14-year-olds in the United States is much higher for children with better educated parents

Source. Adapted by the author from Bradbury et al. (2015)

Pictures of this sort have been, and can easily continue to be, provided by the Organisation for Economic Co-operation and Development (OECD) Programme for International Student Assessment (PISA) for similarly aged children in many rich countries. They should form a part of any dashboard of statistics associated with equality of opportunity among many more countries as they focus on indicators of skills and competencies, rather than education expenditures and inputs. The OECD tends to focus on a continuous index of competency that certainly has its merits, but loses something as a communication device. These indices 
can be directly associated with particular levels of competency that are more directly grasped in public policy, and they should be derived and communicated in this form.

But a continuous index reflecting a more finely nuanced notion of skills and competency also has a central place in Roemer's framework. $\mathrm{He}$ encourages use of the empirical cumulative distribution functions categorised by family circumstances, and proposes that equality of opportunity is reflected in the degree to which these functions are the same (Roemer \& Trannoy 2016). If similarly ranked children across family-background types attain the same level of competency, then this indicates equality of opportunity. His view is that the rankings within socio-economic groups are a marker for 'effort'. The implication is that a top-ranked child among children of low-educated parents is similar in this sense to a top-ranked child among those with high-educated parents. If the former has less developed skills and competencies along some relevant domain for adult success, then this is the role of 'circumstance', indicating inequality of opportunity. The cumulative distribution functions across groups are comprehensive indicators of these populations, and the extent to which they differ, or even differ at particular points in the distribution, is a measure of inequality of opportunity.

Figure 2.4 offers an example. These are the same data used in Figure 2.3, but with a continuous indicator of mathematics skill, and displayed in the way Roemer suggests by offering on the vertical axis the cumulative percentage of children that have reached no more than a particular skill level indicated along the horizontal axis. The horizontal gaps between the curves indicate inequality of opportunity, if we accept that parental education is a circumstance in the sense used by Roemer. These gaps are widest in the broad middle of the distribution: the median ranked child of all children with parents having low education has a competency in mathematics much lower than the average test score, and notably lower than his or her counterpart with high educated parents, who scores well above the average. Equality of opportunity is evident where a child is extremely gifted: the achievement gaps of top percentile children being very small. But even among the top there is a significant gap in achievement. The children scoring in the top decile of the distribution of all children with low-education parents close somewhat the achievement gap relative to the top 10 per cent with medium-educated parents. But both groups - in spite of surely having nurtured talent, expending effort, or having innate ability - still score lower than the top decile from parents 
with college degrees. All of this leaves unquestioned the fact that, for the great bulk of the distribution, achievement is clearly distinguished by family background.

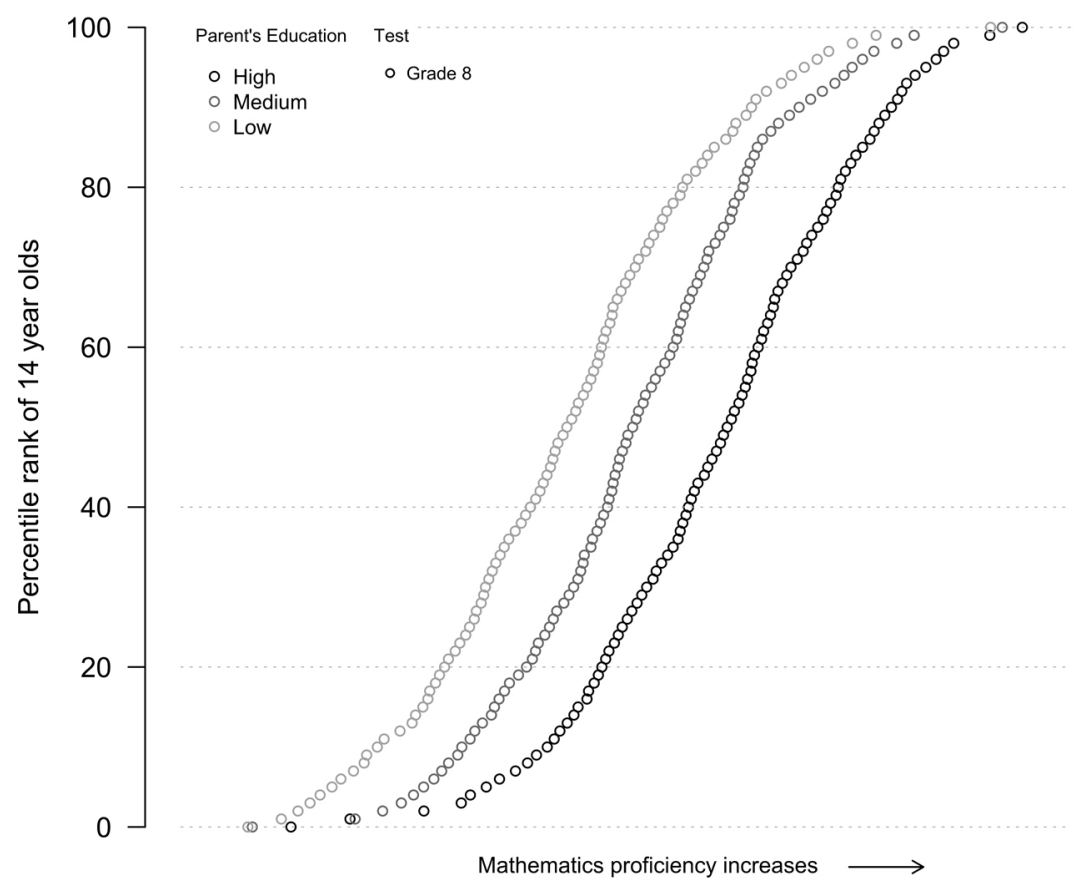

Figure 2.4. Roemer's equality-of-opportunity framework suggests organising test scores as cumulative distribution functions by family background, with achievement differences of similarly ranked students across groups indicating inequality of opportunity among Grade 8 students in the United States

Source. Adapted by the author from Bradbury et al. (2015)

These results are conditional on children being in their early to mid-teens. These results are powerful in better understanding how to design education policies for high school and adolescent years, but it may be misguided if the theory of child development wrapped up in our discussion of equation (2) is correct. If the early years also matter, then inequality of opportunity may be embedded in societal outcomes well before children reach the teen years. If we are to take the focus on children seriously, then indicators of equality of opportunity need to be provided at younger ages, particularly on the cusp of formal schooling so that family versus societal influences can have a hope of being distinguished. 
Figure 2.5 adds the cumulative distribution function of standardised math scores collected at roughly age five, when these American children were starting kindergarten, to the information in Figure 2.4. The cumulative distribution functions are similar, whether measured at age five or 14 . The differences in outcomes by parental education are evident when children first enter the schooling system, and do not change significantly during the years in primary education. This suggests both that the early years are very important in determining life chances, and also that the primary school system has accomplished little in offering disproportionate advantages to the relatively disadvantaged. I should emphasise that an analysis of this sort does not require a longitudinal survey of children, only a series of repeated cross-sections across countries, and at crucial ages in child development that have already been highlighted by the academic literature.

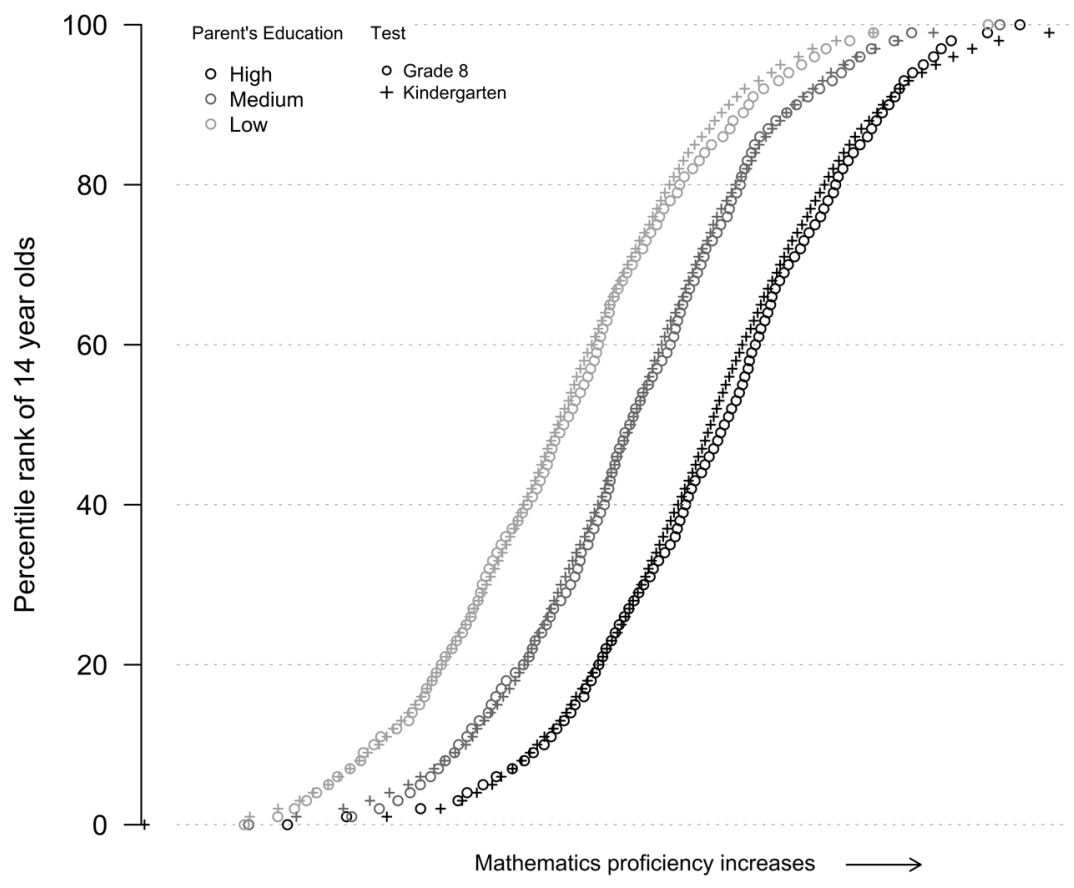

Figure 2.5. Roemer's equality-of-opportunity framework suggests organising test scores as cumulative distribution functions by family background, with achievement differences of similarly ranked students across groups indicating inequality of opportunity among Grade 8 and Kindergarten students in the United States

Source. Adapted by the author from Bradbury et al. (2015) 


\section{Conclusions}

Equality of opportunity should be an aspect of how we understand economic performance and social progress. It puts a focus on process, not just on outcomes. It may be challenging to discern in a rigorous way, relying as it does on an inherent value judgement to distinguish between 'circumstance' and 'effort'. While theorists and philosophers will continue to debate its definition, the notion of equality of opportunity rings true at some basic level for many citizens of both rich and less rich countries. For this reason alone, practitioners should grasp firmly onto whatever theoretical threads they can in order to offer up practical indicators that are useful both to describe societies, and to guide policy interventions.

There is no measurement without theory, and I suggest three lessons for the development of useful indicators. These involve firstly uncovering existing data that is useful for the calculation of standard summary measures of intergenerational mobility, developing new data for this purpose from administrative sources, and enhancing existing surveys with retrospective information. Second, common descriptive statistics of mobility across generations should be complemented with other measures that speak more directly to policy concerns, including measures of absolute mobility and an associated poverty rate based on the minimal level of resources needed to reasonably lower the risk of the intergenerational transmission of low status. Finally, an ideal dashboard of statistics to gauge equality of opportunity would involve organising existing information and developing new instruments to chart the relationship between family background and child development through the whole series of transitions that children make on their way to becoming successful and self-sufficient adults.

\section{References}

Becker, GS \& Tomes, N (1979). 'An equilibrium theory of the distribution of income and intergenerational mobility', Journal of Political Economy, 87(6), 1153-89. doi.org/10.1086/260831.

(1986). 'Human capital and the rise and fall of families', Journal of Labor Economics, 4(3), Part 2, S1-S39. doi.org/10.1086/298118. 
Björklund, A \& Jäntti, M (2011). 'Intergenerational income mobility and the role of family background'. In W Salverda, B Nolan \& T Smeeding (eds), The Oxford handbook of economic inequality (pp 491-521). Oxford University Press. doi.org/10.1093/oxfordhb/9780199606061.013.0020.

Black, SE \& Devereux, PJ (2011). 'Recent developments in intergenerational mobility'. In D Card \& O Ashenfelter (eds), Handbook of labor economics, Vol. 4, Part B (pp 1487-541). Elsevier. doi.org/10.1016/S0169-7218(11) 02414-2.

Blanden, J (2013). 'Cross-country differences in intergenerational mobility: A comparison of approaches from economics and sociology', Journal of Economic Surveys, 27(1), 38-73. doi.org/10.1111/j.1467-6419.2011.00690.x.

Bradbury, B, Corak, M, Waldfogel, J \& Washbrook, E (2015). Too many children left behind: The US achievement gap in comparative perspective. New York: Russell Sage Foundation.

Chetty, R, Hendren, N, Kline, P \& Saez, E (2014). 'Where is the land of opportunity? The geography of intergenerational mobility in the United States', Quarterly Journal of Economics, 129(4), 1553-623. doi.org/10.1093/ qje/qju022.

Corak, M (2006). 'Do poor children become poor adults? Lessons from a crosscountry comparison of generational earnings mobility'. In J Creedy \& G Kalb (eds), Research on economic inequality, Vol. 13 (pp 143-88). Amsterdam: Elsevier. doi.org/10.1016/S1049-2585(06)13006-9.

- (2013). 'Income inequality, equality of opportunity, and intergenerational mobility', Journal of Economic Perspectives, 27(3), 79-102. doi.org/10.1257/ jep.27.3.79.

(2016). Economic theory and practical lessons for measuring equality of opportunities, OECD Statistics Working Papers, No. 2016/02. Paris.

(2018). 'The Canadian geography of intergenerational income mobility', The Economic Journal, uez019. doi.org/10.1093/ej/uez019.

Heckman, JJ \& Mosso, S (2014). The economics of human development and social mobility, No. 19925, NBER Working Paper. Cambridge, Mass.: National Bureau of Economic Research. doi.org/10.3386/w19925.

Mulligan, CB (1997). Parental priorities and economic inequality. University of Chicago Press. 
Narayan, A, van der Weide, R, Cojocaru, A, Lakner, C, Redaelli, S, Gerszon Mahler, D, Ramasubbaiah, RGN \& Thewissen, S (2018). Fair progress? Economic mobility across generations around the world. Washington DC: World Bank. doi.org/10.1596/978-1-4648-1210-1.

Roemer, J (2000). Equality of opportunity. Cambridge, Mass.: Harvard University Press.

- (2004). 'Equal opportunity and intergenerational mobility: Going beyond intergenerational income transition matrices'. In M Corak (ed.), Generational income mobility in North America and Europe (pp 48-57). Cambridge University Press.

Roemer, J \& Trannoy, A (2016). 'Equality of opportunity: Theory and measurement', Journal of Economic Literature, 54(4), 1288-332. doi.org/ 10.1257/jel.20151206.

Solon, G (1999). 'Intergenerational mobility in the labor market', In OC Ashenfelter \& D Card (eds), Handbook of labor economics, Vol. 3A (pp 1761-800). Amsterdam: Elsevier Science. doi.org/10.1016/S15734463(99)03010-2.

- (2002). 'Cross-country differences in intergenerational earnings mobility', The Journal of Economic Perspectives, 16(3), 59-66. doi.org/10.1257/ 089533002760278712 .

(2004). 'A model of intergenerational mobility variation over time and place'. In M Corak (ed.), Handbook of labor economics (pp 38-47). Cambridge University Press. 
This text is taken from Achieving Inclusive Growth in the Asia Pacific, edited by Adam Triggs and Shujiro Urata, published 2020 by ANU Press, The Australian National University, Canberra, Australia.

doi.org/10.22459/AIGAP.2020.02 